\title{
Cervical myelopathy secondary to omovertebral bone in the pediatric patient with Sprengel deformity
}

\author{
Hashem T. Al-Salman, MBBS, Abdulmonem A. Al-Hussien, MBBS, Ibrahim H. Al-Ahmed, MBBS.
}

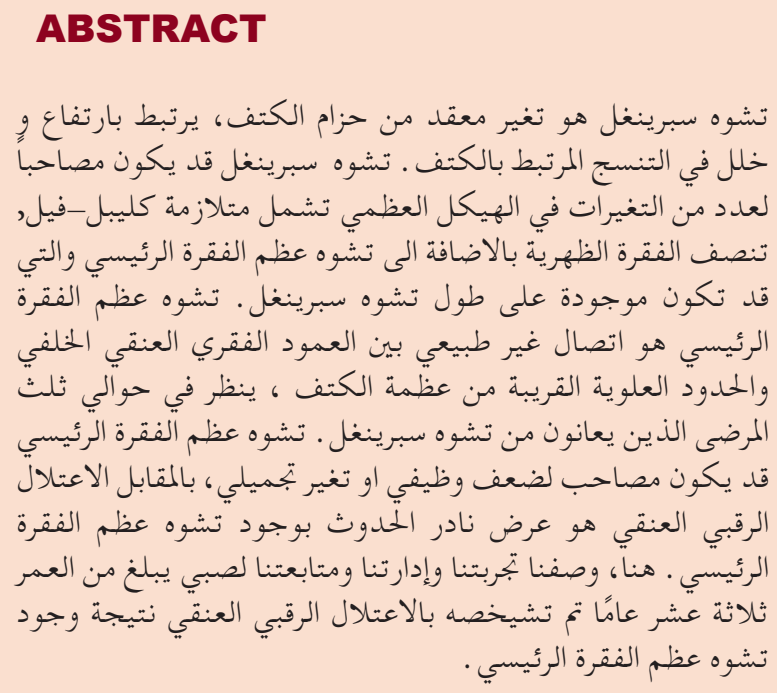

Sprengel deformity is a congenital anomaly arising mainly in the shoulder girdle, associated with elevation of dysplastic scapula. skeletal anomalies, mainly Klippel-Feil syndrome, hemivertebrae, and omovertebral bone may be present along Sprengel anomaly. The omovertebral bone is an abnormal bone that originates from the superomedial edge of the scapula with different insertion points along the posterior cervical spine, seen in about third of the patients with Sprengel anomaly. While cosmetic to functional impairment is a common presentation to the omovertebral bone, cervical myelopathy is a rare presentation. Here, we described our experience, management and follow up of 13-year-old boy presented with cervical myelopathy secondary to the omovertebral bone.

Neurosciences 2021; Vol. 26 (1): 89-92 doi: 10.17712/nsj.2021.1.20200040

From the Department of Neurosurgery, King Fahad Hospital, Hofuf, Al-Ahasa, Kingdom of Saudi Arabia

Received 7th July 2020. Accepted 17th March 2020.

Address correspondence and reprint request to: Dr. Hashem Alsalman, Department of Neurosurgery, King Fahad Hospital, Al-Ahasa, Kingdom of Saudi Arabia.E-mail: hts_802@hotmail.com ORCID : https://orcid.org/0000-0002-3447-0540
Sprengel deformity is a complex anomaly of the Shoulder girdle, associated with elevation of dysplastic scapula. ${ }^{1-4}$ Clinically, it is associated with disfigurement and limitation of shoulder movement. Other skeletal anomalies - mainly, Klippel-Feil syndrome, hemivertebrae, and omovertebral bone may be present. ${ }^{4}$ The omovertebral bone is an abnormal bone that originates from the superomedial edge of the scapula with different insertion points along the posterior cervical spine, seen in about a third of patients with Sprengel anomaly., The clinical presentation ranges from cosmetic to functional impairment, while cervical myelopathy is a rare presentation related to omovertebral bone. The management and follow up is less described in the literature contributed to its rare occurance. ${ }^{6}$ Here, the author described a 13 -year- old boy diagnosed with Sprengel deformity presented with myelopathic manifestation, where cervical magnetic resonance imaging (MRI) showed signal cord changes secondary to compression by intraspinal extension of the omovertebral bone. The patient underwent uneventful resection of the abnormal bone, and spinal cord decompression.

Case Report. Patient perspectives. This 13- yearold boy, presented with a history of imbalance and lower limb stiffness for 3 months.

Clinical findings. Physical examination showed hyper-reflexia in the left knee and ankle jerk without clonus, in addition to positive Babinski sign in the left lower limb. There was bilateral elevation of both scapula when the patient undressed, which represents grade 1 based on the Cavendish classification for Sprengel deformity $^{3}$ (Table 1).

Diagnostic assessment. The CT of the cervical spine showed abnormal bone extending from the C3/4 vertebrae to the level of C6 (Figure $1 \mathrm{~A}, \mathrm{~B}$ ). MRI the

Disclosure. The authors declare no conflicting interests, support or funding from any drug company. 
cervical spine showed impingement of the omovertebral bone over the dorsal aspect of the spinal cord, with signal cord changes (Figure $2 \mathrm{~A}, \mathrm{~B}$ ).

Therapeutic intervention. Patient underwent C4 laminectomy and complete resection of the omovertebral bone (Figure $3 \mathrm{~A}, \mathrm{~B}$ ).

Follow up and outcome. Postoperatively, the patient has his baseline preoperative neurologic status with no deterioration.
Discussion. Sprengel deformity is a congenital anomaly arising mainly in the shoulder girdle, associated with elevation of dysplastic scapula. it is occurred secondary to defect in the signaling of the germ layer differentiation between third and fifth weks of embryonic peroid. ${ }^{5}$ One-third of Sprengel deformity patients develop an omovertebral bone anomaly, which is described as bone attachment originating from ridge of the scapula with different insertion points to the spinous process, lamina, or transverse process of the

Table 1 - Cavendish classification.

\begin{tabular}{lr}
\hline Grades & Clinical features \\
\hline 1 & Very mild deformity is observed. When covered with clothes the deformity is almost invisible. \\
2 & The deformity is still mild, but appears as bump. The superomedial portion of the high scapula is convex, forming a bump. \\
3 & Moderate deformity with $2-5 \mathrm{~cm}$ visible elevation of the affected shoulder compared to normal one \\
4 & Severe deformity with $>5 \mathrm{~cm}$ elevation of the affected shoulder accompained by neck webbing. \\
\hline & Reproduced with permission from: Dilli A, Ayaz UY, Damar C, Ersan O, Hekimoglu B. Sprengel deformity: magnetic resonance \\
& imaging findings in two pediatric cases. J Clin Imaging Sci 2011; 1: 13.
\end{tabular}
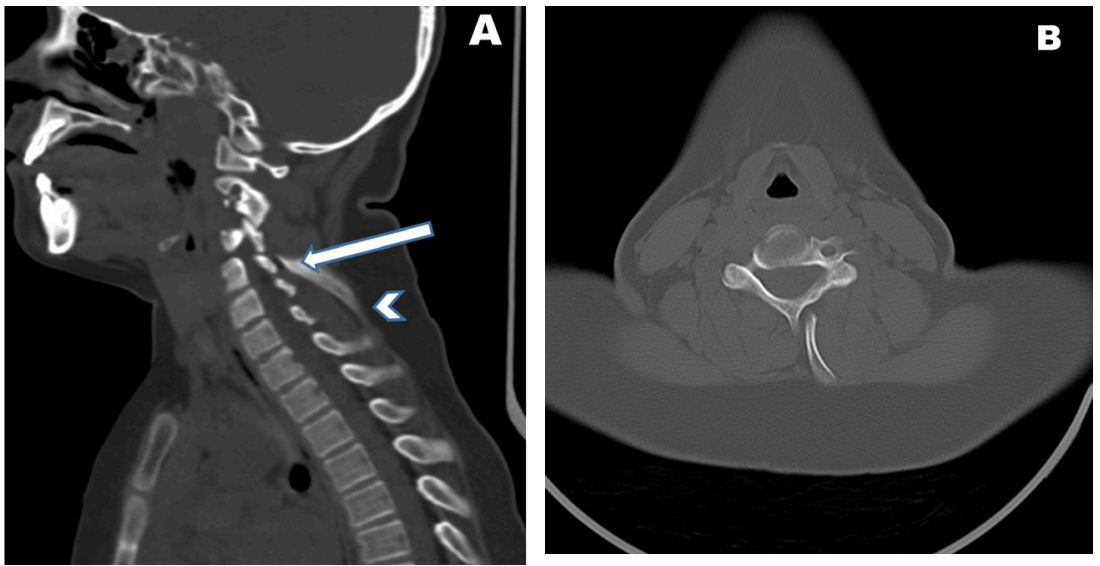

Figure 1 - CT cervical spine A) sagittal view with extension of the omovertebral bone dorsally at level of C4 arrow indicate lamina of C4), arrow head indicate the downward extension of omovertebral bone), B) axial view showed the presence of omovertebral bone at the level of C4 vertebrae
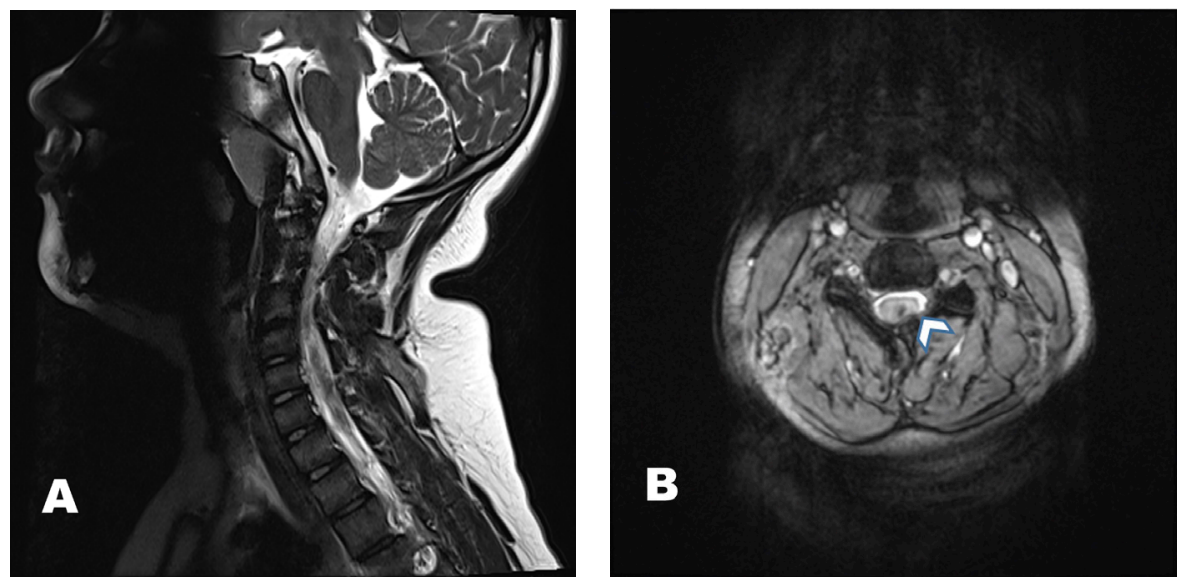

Figure 2 - MRI cervical spine A) showed impingement of the omovertebral bone over the dorsal aspect of the spinal cord, B) Arrow head showed loss of CSF signal with spinal cord impingement at C4 level. 

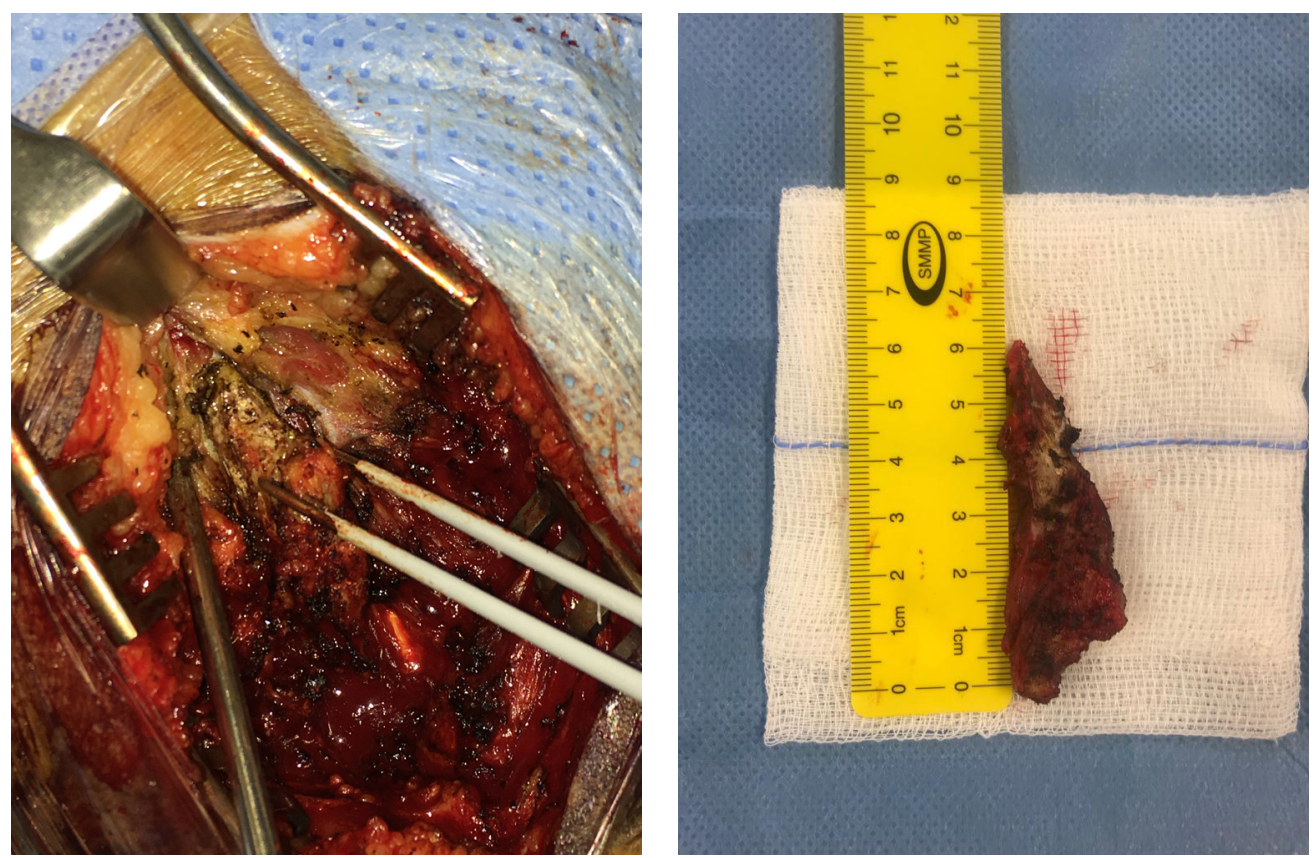

Figure 3 - Intraoperative view A) Intraoperative exposure of the omovertebral bone before completely resected, B) showed the bone after complete resection which measured $6 \mathrm{~cm}$ in its length.

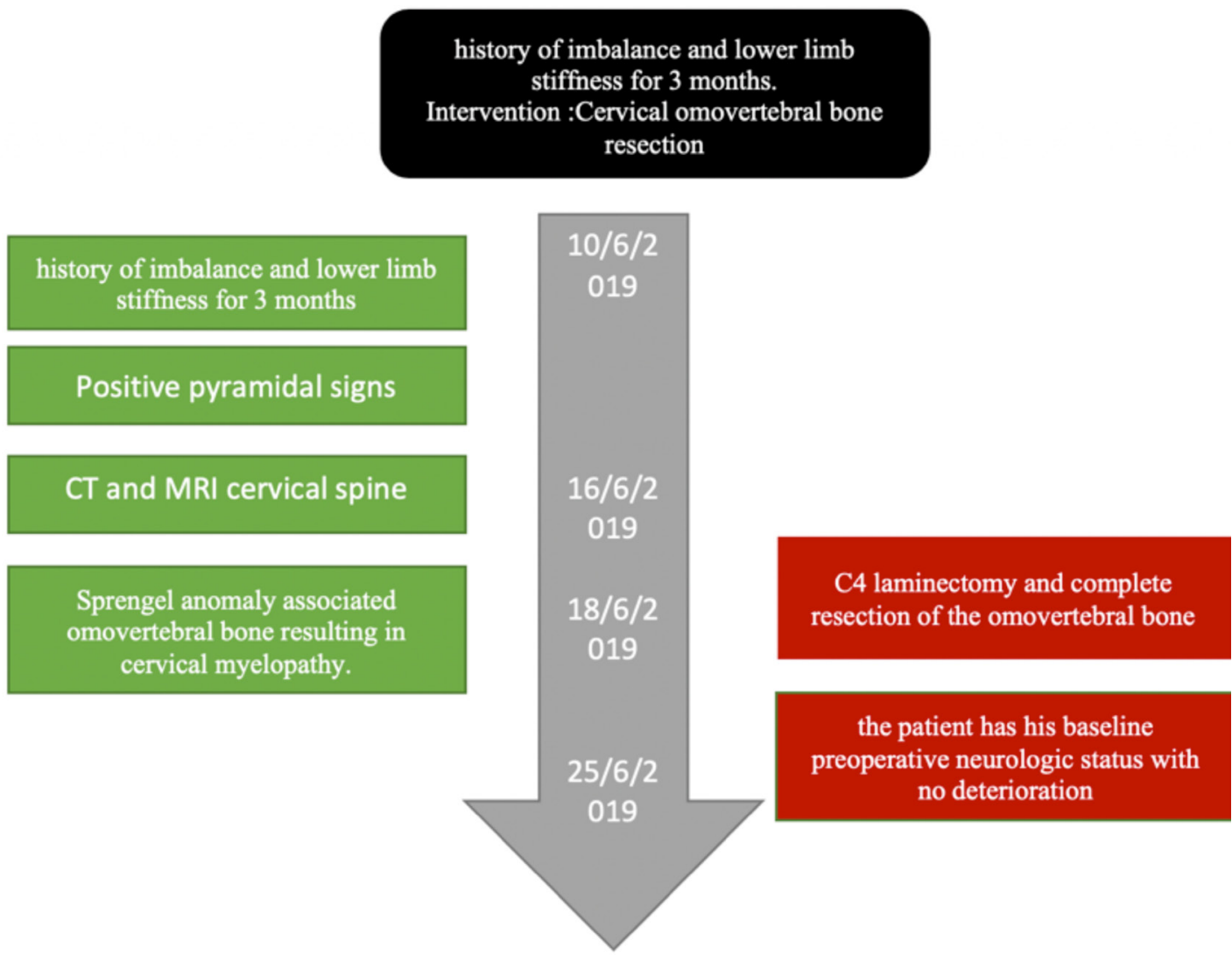

Figure 4 - Timeline of patient's clinical condition and management. 
cervical vertebrae. The omovertebral bone is usually limited to one side and thought to play a major role in malpositioning of the scapula. ${ }^{2}$

Willet et $\mathrm{al}^{8}$ was pioneered in describing the omovertebral bone and its resection, also explaining the three hypotheses for its etiology: (1) it is developed from the vertebrae, either as an extra growth of the spinous process or as an excessive development of the lateral projecting process called "hyperapophyses"; (2) it originates from the scapula and becomes fused with the cervical vertebrae by an overgrowth of the epiphysis on the posterior border of the scapula; (3) it develops independently of the spine and scapula as an ossification of the connective tissue between the posterior deep cervical muscles. ${ }^{8,9}$ The natural history of the omovertebral bone is progressive, as it is associated with calcification and with limitation of shoulder range of motion.

Treatment options for Sprengel deformity associated with omovertebral bone are influenced by different factors, including the degree of limitation of shoulder abduction, presence of myelopathy symptoms and age of the patient. ${ }^{6}$ Surgical correction in adult patients presenting with deformity is controversial. Doita et $\mathrm{al}^{4}$ described a good result in terms of shoulder range of motion after surgical correction in 2 adult patients. A less satisfactory result has been associated with late presentation of Sprengel deformity. However, Gillespie $\mathrm{B}$ et $\mathrm{al}^{7}$ reported good outcomes after surgical correction for a patient with late presentation of Sprengel deformity.

In the literature, only one case of an adult patient with Sprengel deformity and omovertebral bone presented with sign and symptoms of cervical myelopathy has been reported. ${ }^{6}$ This was managed with spinal decompression and resection of the omovertebral bone. Here, we described the first case for a pediatric patient with Sprengel deformity presented with myelopathy secondary to compression by the omovertebral bone.

The decision to proceed with surgery in cases of mild Sprengel deformity with the omovertebral bone is challenging due to the lack of clearly established guidelines. In our illustrated condition, the surgical option was chosen based on the clinical and radiological picture of the patient.

In conclusion, presentation of Sprengel deformity and omovertebral bone with myelopathic manifestation is rare. Here, we described a pediatric patient with cervical myelopathy secondary to compression by the omovertebral bone associated with mild sprengel deformity. Due to the lack of established guidelines for the management of mild Sprengel deformity, the surgical decision is usually challenging. Further descriptive studies are encouraged to formulate when it is indicated to proceed to surgical intervention rather than conservative option.

\section{References}

1. Boon JM, Potgieter D, Van Jaarsveld Z, Frantzen DJ. Congenital undescended scapula (Sprengel deformity): a case study. Clin Anat 2002; 15: 139-142.

2. Cho TJ, Choi IH, Chung CY, Hwang JK. The Sprengel deformity. Morphometric analysis using 3D-CT and its clinical relevance. J Bone Joint Surg Br 2000; 82: 711-718.

3. Dilli A, Ayaz UY, Damar C, Ersan O, Hekimoglu B. Sprengel deformity: magnetic resonance imaging findings in two pediatric cases. J Clin Imaging Sci 2011; 1: 13.

4. Doita M, Iio H, Mizuno K. Surgical management of Sprengel's deformity in adults. A report of two cases. Clin Orthop Relat Res 2000; 371: 119-124.

5. Kafadar C, Saglam M, Sonmez G, Mutlu H. Omovertebral bone associated with Sprengel deformity presented with chronic cervical pain. Spine J 2016; 16: e43.

6. Füllbier L, Tanner P, Henkes H, Hopf NJ. Omovertebral bone associated with Sprengel deformity and Klippel-Feil syndrome leading to cervical myelopathy. J Neurosurg Spine 2010; 13: 224-228.

7. Gillespie B, Shaw BA, Waters P. Surgical Excision of an Omovertebral Bone in an Adult with Untreated Sprengel Deformity: A Case Report. JBJS Case Connect 2013; 3: 1-6.

8. Pu Q, Huang R, Brand-Saberi B. Development of the shoulder girdle musculature. Dev Dyn 2016; 245: 342-350.

9. Williams MS. Developmental anomalies of the scapula-the "omo"st forgotten bone. Am J Med Genet A 2003; 120A: 583-587. 